\title{
Presepsin and prognostic nutritional index are predictors of septic acute kidney injury, renal replacement therapy initiation in sepsis patients, and prognosis in septic acute kidney injury patients: a pilot study
}

Yuichiro Shimoyama ${ }^{1 *}$, Osamu Umegaki ${ }^{1}$, Noriko Kadono ${ }^{1}$ and Toshiaki Minami ${ }^{2}$

\begin{abstract}
Background: Sepsis is the most common cause of acute kidney injury (AKI) among critically ill patients. This study aimed to determine whether presepsin is a predictor of septic acute kidney injury, renal replacement therapy initiation (RRTi) in sepsis patients, and prognosis in septic AKI patients.

Methods: Presepsin values were measured immediately after ICU admission (baseline) and on Days 2, 3, and 5 after ICU admission. Glasgow Prognostic Score (GPS), neutrophil to lymphocyte ratio (NLR), platelet to lymphocyte ratio, Prognostic Index, and Prognostic Nutritional Index (PNI) were measured at baseline, and total scores ("inflammationpresepsin scores [iPS]") were calculated for category classification. Presepsin values, inflammation-based prognostic scores, and iPS were compared between patients with and without septic AKI or RRTi and between survivors and non-survivors.
\end{abstract}

Results: Receiver operating characteristic curve analyses identified the following variables as predictors of septic AKI and RRTi in sepsis patients: presepsin on Day 1 (AUC: 0.73) and Day 2 (AUC: 0.71) for septic AKI, and presepsin on

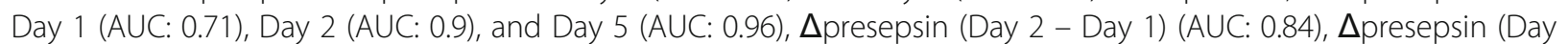
5 - Day 1) (AUC: 0.93), and PNI (AUC: 0.72) for RRTi. Multivariate logistic regression analyses identified presepsin on Day 2 as a predictor of prognosis in septic AKI patients.

Conclusions: Presepsin and PNI were found to be predictors of septic AKI, RRTi in sepsis patients, and prognosis in septic AKI patients.

Keywords: Presepsin, Sepsis, Sepsis-3 definition, Inflammation-based prognostic scores, Acute kidney injury, Renal replacement therapy

\footnotetext{
* Correspondence: shimocchiliebesfreud512@yahoo.co.jp

'Department of Anesthesiology, Osaka Medical College, Intensive Care Unit,

Osaka Medical College Hospital, 2-7 Daigaku-machi, Takatsuki, Osaka

569-8686, Japan

Full list of author information is available at the end of the article
}

(c) The Author(s). 2021 Open Access This article is licensed under a Creative Commons Attribution 4.0 International License, which permits use, sharing, adaptation, distribution and reproduction in any medium or format, as long as you give appropriate credit to the original author(s) and the source, provide a link to the Creative Commons licence, and indicate if changes were made. The images or other third party material in this article are included in the article's Creative Commons licence, unless indicated otherwise in a credit line to the material. If material is not included in the article's Creative Commons licence and your intended use is not permitted by statutory regulation or exceeds the permitted use, you will need to obtain permission directly from the copyright holder. To view a copy of this licence, visit http://creativecommons.org/licenses/by/4.0/ The Creative Commons Public Domain Dedication waiver (http://creativecommons.org/publicdomain/zero/1.0/) applies to the data made available in this article, unless otherwise stated in a credit line to the data. 


\section{Background}

Sepsis is the main cause of mortality in critically ill intensive care unit (ICU) patients [1], and new sepsis criteria were established in 2016 [2]. Sepsis is the most common cause of acute kidney injury (AKI) among critically ill patients [3]. Early treatment with appropriate antibiotics improves the prognosis and survival of severe sepsis and septic shock patients [4-6].

Procalcitonin (PCT) is the main biomarker used to diagnose sepsis [7], but its values increase in non-sepsis pathologies as well [8-10]. Presepsin is a subtype of soluble CD14 (CD14-ST) [11], and is an accurate biomarker for diagnosing sepsis. Presepsin has a higher specificity for sepsis diagnosis compared with PCT and IL-6 [12], and thus could be useful for the prognosis of sepsis and monitoring the course of the disease [13]. Another advantage of presepsin is that it can be measured in less than $17 \mathrm{~min}$ with a compact fully automated immunoanalyzer (PATHFAST; ${ }^{\oplus}$ Mitsubishi Chemical Medience Corporation, Tokyo, Japan) [14].

The Glasgow Prognostic Score (GPS; based on serum C-reactive protein (CRP) and albumin levels), neutrophil to lymphocyte ratio (NLR), platelet to lymphocyte ratio (PLR), Prognostic Nutritional Index (PNI; based on albumin and lymphocyte counts), and the Prognostic Index (PI; based on serum CRP and white blood cell counts), are inflammation-based prognostic scores which are useful prognostic biomarkers for many types of cancer [15]. However, no study has investigated the association of septic acute kidney injury (AKI), renal replacement therapy initiation (RRTi), and prognosis of septic AKI with presepsin values alone or in combination with the above-mentioned inflammation-based prognostic scores in septic ICU patients.

The present study aimed to prove the following hypotheses: 1) presepsin can predict septic AKI, RRTi in sepsis ICU patients, and prognosis in septic AKI ICU patients; and 2) the ability of presepsin to predict the above are superior to inflammation-based prognostic scores and can be improved by combining presepsin values with inflammation-based prognostic scores.

\section{Methods}

\section{Patients and study design}

The study design, inclusion and exclusion criteria, and definition of "inflammation-presepsin scores [iPS]" used in the present study were published previously [16]. Septic AKI was defined as stage $\geq 1$ kidney disease according to the Kidney Disease: Improving Global Outcomes (KDIGO) classification [17]. The need for RRTi was determined according to the KDIGO classification (i.e., stage $>3$ kidney disease). Presepsin values, inflammation-based prognostic scores, iPS, and changes $(\Delta)$ in presepsin values relative to baseline values at each sampling point were compared between patients with and without septic AKI or RRTi and between survivors and non-survivors.

\section{Laboratory assessments}

Presepsin concentration was measured by PATHFAST ${ }^{\circledR}$ (Mitsubishi Chemical Medience Corporation, Tokyo, Japan) [14]. Threshold values were as follows: (a) 300 to 500 pg/ml: "systemic infection (sepsis) possible"; (b) 500 to $1000 \mathrm{pg} / \mathrm{ml}$ : "significant risk of systemic infection progression (severe sepsis), increased risk of unfavorable outcome"; and (c) $\geq 1000 \mathrm{pg} / \mathrm{ml}$ : "High risk of systemic infection progression (severe sepsis/septic shock). High risk for mortality after 30 day comparable with a SOFA score $\geq 8 ”[18,19]$.

\section{Statistical analysis}

Categorical data are reported as percentages and compared using Fisher's exact test. Continuous data are reported as medians with inter-quartile ranges and compared using the Mann-Whitney U test. ROC curves were generated for presepsin values, inflammation-based prognostic scores, iPS, and $\Delta$ presepsin, and areas under the curve (AUCs), cut-off values, sensitivities, and specificities were calculated. For all values of presepsin, inflammation-based prognostic scores, iPS, and $\Delta$ presepsin, Kaplan-Meier curves were constructed for each mortality category, and the log-rank test was performed. Presepsin values on Day 1 and Day 2, inflammationbased prognostic scores, and iPS were examined further by multivariate logistic regression analysis for septic AKI, RRTi in sepsis patients, and prognosis in septic AKI patients. $P<0.05$ was considered statistically significant. JMP software version 11.00 (SAS Institute Inc., $\mathrm{NC}$, USA) was used for all statistical analyses.

\section{Results}

Baseline characteristics of 83 adult patients diagnosed with sepsis according to the Sepsis-3 definition and admitted to the ICU are shown in Table 1. Median age was 74 years (range: 65.5-78.5). No significant differences were observed in age and sex in septic AKI patients and RRTi patients (Table 2).

There were 38 septic AKI patients defined as stage $\geq 1$ according to the KDIGO classification, and 6 underwent RRTi after ICU admission. Of these, one patient withdrew from continuous renal replacement therapy, one patient's end-stage kidney disease worsened, and four patients died during their ICU stay. ROC curve analyses revealed the following cut-off values (Table 3): AKI: $708.0(\mathrm{pg} / \mathrm{ml})$ for presepsin on Day 1 (AUC, 0.73; sensitivity, 81.6\%; specificity, 58.5\%) and $985.0(\mathrm{pg} / \mathrm{ml})$ for presepsin on Day 2 (AUC, 0.71; sensitivity, $65.5 \%$; specificity, 64.3\%); RRTi: 2014.0 (pg/ml) for presepsin on Day 
Table 1 Baseline demographic characteristics

\begin{tabular}{|c|c|c|}
\hline Variable & $n=83$ & \\
\hline Age (years) & 74.0 & $(65.5-78.5)$ \\
\hline Sex (male) (\%) & 51.0 & $(61.4)$ \\
\hline Cancer (\%) & 40.0 & $(48.2)$ \\
\hline Coronary artery disease (\%) & 4.0 & $(4.8)$ \\
\hline Diabetes mellitus (\%) & 10.0 & $(12.0)$ \\
\hline Hypertension (\%) & 21.0 & $(25.3)$ \\
\hline Albumin (g/dL) & 2.3 & $(1.8-3.0)$ \\
\hline CRP $(\mathrm{mg} / \mathrm{dL})$ & 10.4 & $(3.7-17.5)$ \\
\hline WBC $\left(\times\left. 10^{9}\right|^{-1}\right)$ & 10.9 & $(5.4-15.4)$ \\
\hline Neutrophil count $\left(\times\left. 10^{9}\right|^{-1}\right)$ & 8.7 & $(3.56-13.29)$ \\
\hline Lymphocyte count $\left(\times\left. 10^{9}\right|^{-1}\right)$ & 0.5 & $(0.299-0.927)$ \\
\hline Plt count $\left(\times 10^{4} \mathrm{~mm}^{-3}\right)$ & 17.8 & $(11.5-26.5)$ \\
\hline Fibrinogen (mg/dL) & 609.0 & $(378-711)$ \\
\hline Survival (dead) (\%) & 26.0 & (31.3) \\
\hline AKI (\%) & 38.0 & $(45.8)$ \\
\hline ARDS (\%) & 13.0 & $(15.7)$ \\
\hline Shock (\%) & 48.0 & $(57.8)$ \\
\hline DIC (\%) & 30.0 & $(36.1)$ \\
\hline Presepsin on Day 1 (pg/mL) & 1051.5 & $(569-1819.3)$ \\
\hline Presepsin on Day 2 (ng/mL) & 1016.5 & $(538-2156)$ \\
\hline Presepsin on Day 3 (ng/mL) & 802.0 & $(480.5-1825)$ \\
\hline Presepsin on Day 5 (ng/mL) & 1043.0 & $(480-1616)$ \\
\hline$\Delta$ Presepsin Day 2 - Day $1(\mathrm{pg} / \mathrm{mL})$ & -21.50 & $(-246.5-274.75)$ \\
\hline$\Delta$ Presepsin Day 3 - Day 1 (pg/mL) & -38.50 & $(-748.5-304)$ \\
\hline$\Delta$ Presepsin Day 5 - Day 1 (pg/mL) & -59.50 & $(-745.75-635.5)$ \\
\hline GPS & 1.0 & $(1-2)$ \\
\hline NLR & 12.6 & $(4.53-26.35)$ \\
\hline PLR & 321.9 & $(195.63-543.69)$ \\
\hline $\mathrm{Pl}$ & 1.0 & $(1-2)$ \\
\hline $\mathrm{PNI}$ & 26.6 & $(21.26-33.72)$ \\
\hline SOFA & 8.0 & $(5-11)$ \\
\hline qSOFA & 2.0 & $(1-3)$ \\
\hline
\end{tabular}

CRP C-reactive protein, WBC white blood cell, AKI acute kidney injury, ARDS acute respiratory distress syndrome, DIC disseminated intravascular coagulation, GPS Glasgow Prognostic Score, NLR neutrophil to lymphocyte ratio, PLR platelet to lymphocyte ratio, PI Prognostic Index, PNI Prognostic Nutritional Index, SOFA Sequential Organ Failure Assessment, qSOFA quick Sequential Organ Failure Assessment

1 (AUC, 0.71; sensitivity, 66.7\%; specificity, 83.3\%), 2867.0 (pg/ml) for presepsin on Day 2 (AUC, 0.90; sensitivity, 75.0\%; specificity, 91.7\%), 3014.0 (pg/ml) for presepsin on Day 5 (AUC, 0.96; sensitivity, 100.0\%; specificity, 92.9\%), $507.0(\mathrm{pg} / \mathrm{ml})$ for $\Delta$ presepsin (Day 2 - Day 1) (AUC, 0.84; sensitivity, 75.0\%; specificity, 80.0\%), $2385.0(\mathrm{pg} / \mathrm{ml})$ for $\Delta$ presepsin (Day 5 - Day 1) (AUC, 0.93; sensitivity, 100.0\%; specificity, 93.3\%), and
Table 2 Predictors of septic AKI and RRT initiation

\begin{tabular}{|c|c|c|}
\hline \multirow[b]{3}{*}{ Variable } & \multirow{3}{*}{$\begin{array}{l}\text { AKI }(n=38) \\
\text { Univariate analysis } \\
P \text {-value }\end{array}$} & \multirow{3}{*}{$\begin{array}{l}\text { RRT initiation }(n=6) \\
\text { Univariate analysis } \\
P \text {-value }\end{array}$} \\
\hline & & \\
\hline & & \\
\hline Age & 0.402 & 0.108 \\
\hline Sex & 0.930 & 0.670 \\
\hline Cancer & 0.236 & 0.383 \\
\hline Coronary artery disease & 0.621 & none \\
\hline Diabetes mellitus & 0.005 & 0.620 \\
\hline Hypertension & 0.010 & 0.368 \\
\hline Albumin & 0.851 & 0.137 \\
\hline CRP & 0.023 & 0.773 \\
\hline WBC & 0.253 & 0.606 \\
\hline Neutrophil & 0.315 & 0.564 \\
\hline Lymphocytes & 0.631 & 0.127 \\
\hline Platelet count & 0.081 & 0.127 \\
\hline Fibrinogen & 0.427 & 0.088 \\
\hline Survival & 0.052 & 0.333 \\
\hline ARDS & 0.069 & 0.035 \\
\hline Shock & 0.080 & 0.641 \\
\hline $\mathrm{DIC}$ & 0.000 & 0.206 \\
\hline Presepsin on Day 1 & 0.001 & 0.149 \\
\hline Presepsin on Day 2 & 0.009 & 0.019 \\
\hline Presepsin on Day 3 & 0.143 & 0.905 \\
\hline Presepsin on Day 5 & 0.185 & 0.053 \\
\hline$\Delta$ Presepsin Day 2 - Day 1 & 0.810 & 0.032 \\
\hline$\Delta$ Presepsin Day 3 - Day 1 & 0.530 & 0.811 \\
\hline$\Delta$ Presepsin Day 5 - Day 1 & 0.408 & 0.053 \\
\hline GPS & 0.232 & 0.832 \\
\hline NLR & 0.969 & 0.837 \\
\hline PLR & 0.032 & 0.458 \\
\hline $\mathrm{PI}$ & 0.220 & 0.575 \\
\hline PNI & 0.696 & 0.091 \\
\hline iPS-GPS & 0.024 & 0.528 \\
\hline iPS-NLR & 0.203 & 0.217 \\
\hline iPS-PLR & 0.877 & 0.242 \\
\hline iPS-PI & 0.025 & 0.782 \\
\hline iPS-PNI & 0.172 & 0.718 \\
\hline SOFA & 0.024 & 0.200 \\
\hline qSOFA & 0.102 & 0.726 \\
\hline
\end{tabular}

AKI acute kidney injury, RRT renal replacement therapy, CRP C-reactive protein, WBC white blood cell, ARDS acute respiratory distress syndrome, DIC disseminated intravascular coagulation, GPS Glasgow Prognostic Score, NLR neutrophil to lymphocyte ratio, $P L R$ platelet to lymphocyte ratio, PI Prognostic Index, PNI Prognostic Nutritional Index, iPS inflammation-presepsin score, SOFA Sequential Organ Failure Assessment, qSOFA quick Sequential Organ Failure Assessment 
Table 3 Receiver operating characteristic curve analysis

\begin{tabular}{|c|c|c|c|c|c|}
\hline Variable & AUC & Cut-off & $P$ value & Sensitivity (\%) & Specificity (\%) \\
\hline \multicolumn{6}{|l|}{ AKI } \\
\hline Presepsin on Day 1 (pg/mL) & 0.73 & 708.00 & $P<0.001$ & 81.6 & 58.5 \\
\hline Presepsin on Day 2 (pg/mL) & 0.71 & 985.00 & 0.002 & 65.5 & 64.3 \\
\hline \multicolumn{6}{|l|}{ RRT initiation } \\
\hline Presepsin on Day 1 (pg/mL) & 0.71 & 2014.00 & 0.155 & 66.7 & 83.3 \\
\hline Presepsin on Day 2 (pg/mL) & 0.90 & 2867.00 & $P<0.001$ & 75.0 & 91.7 \\
\hline Presepsin on Day 5 (pg/mL) & 0.96 & 3014.00 & $P<0.001$ & 100.0 & 92.9 \\
\hline$\Delta$ Presepsin Day 2 - Day 1 (pg/mL) & 0.84 & 507.00 & 0.002 & 75.0 & 80.0 \\
\hline$\Delta$ Presepsin Day 5 - Day 1 (pg/mL) & 0.93 & 2385.00 & $P<0.001$ & 1.0 & 93.3 \\
\hline PNI & 0.72 & 19.51 & 0.145 & 66.7 & 93.5 \\
\hline
\end{tabular}

AUC area under the curve, $A K I$ acute kidney injury, RRT renal replacement therapy, PNI Prognostic Nutritional Index

19.5 for PNI (AUC, 0.72; sensitivity, 66.7\%; specificity, 93.5\%).

Regarding prognosis in septic AKI patients, the results of ROC curve analyses, Log-rank test, and univariate analysis are shown in Tables 4, 5, and 6, respectively. ROC curve analyses revealed the following cutoff values: 28-day mortality: $1373.0(\mathrm{pg} / \mathrm{ml})$ for presepsin on Day 1 (AUC, 0.77; sensitivity, 81.8\%; specificity, 76.9\%), 1581.0 $(\mathrm{pg} / \mathrm{ml})$ for presepsin on Day 2 (AUC, 0.83; sensitivity, 85.7\%; specificity, 68.2\%), and 1.0 for iPS-PLR (AUC, 0.75; sensitivity, $90.9 \%$; specificity, $46.2 \%$ ); 60 -day mortality: $1373.0(\mathrm{pg} / \mathrm{ml})$ for presepsin on Day 1 (AUC, 0.70; sensitivity, 75.0\%; specificity, 76.0\%), $1581.0(\mathrm{pg} / \mathrm{ml})$ for presepsin on Day 2 (AUC, 0.73; sensitivity, $75.0 \%$; specificity, 66.7\%), and 1.0 for iPS-PLR (AUC, 0.70; sensitivity, 83.3\%; specificity, 44.0\%); 90-day mortality: 1373.0 (pg/ $\mathrm{ml}$ ) for presepsin on Day 1 (AUC, 0.65; sensitivity, 64.3\%; specificity, 73.9\%) and $1581.0(\mathrm{pg} / \mathrm{ml})$ for presepsin on Day 2 (AUC, 0.65; sensitivity, 60.0\%; specificity, 63.2\%); 180-day mortality: $1336.0(\mathrm{pg} / \mathrm{ml})$ for presepsin on Day 1 (AUC, 0.65; sensitivity, 66.7\%; specificity, $68.2 \%$ ) and $1581.0(\mathrm{pg} / \mathrm{ml})$ for presepsin on Day 2 (AUC, 0.68; sensitivity, 63.6\%; specificity, 66.7\%) (Table 4). In the log-rank test, presepsin on Day $1(p=0.003)$, PNI $(p=0.001)$, and iPS-PLR $(p=0.036)$ were significant predictors of 28-day mortality, and presepsin on Day 1 ( $p=$ $0.007)$ and PNI $(p=0.003)$ were significant predictors of 60-day mortality (Table 5). In the univariate analysis, fibrinogen was a significant predictor of 28-day mortality $(p=0.0019), 60$-day mortality $(\mathrm{p}=0.0019), 90$-day mortality $(p=0.0026)$, and 180 -day mortality $(p=0.0043)$ (Table 6).

We also performed multivariate logistic regression analyses to identify independent predictors of septic AKI, RRTi in septic patients, and prognosis in septic AKI patients (Table 7). Multivariate logistic regression analyses revealed that presepsin on Day 2 is a predictor of prognosis in septic AKI patients.

\section{Discussion}

Sepsis involves lethal organ dysfunction due to the activation of both pro- and anti-inflammatory responses [20], and is modified by non-immunologic pathways, including cardiovascular, neuronal, autonomic, hormonal, bioenergetic, metabolic, and coagulation pathways [2123]. Severe sepsis is associated with a mortality rate of $>$ $50 \%$ [24], and the most common cause of AKI among critically ill patients is sepsis [3]. PCT has the highest specificity among diagnostic markers for sepsis, but can yield false positive results since its levels increase in various non-sepsis contexts (e.g., severe trauma, invasive surgical procedure, critical burn injuries) [8-10]. Presepsin, another diagnostic marker for sepsis, is secreted from granulocytes in response to infectious stimuli in an animal sepsis model [25]. According to Liu et al., presepsin was the best predictor of early stage sepsis in emergency department patients [26]. Presepsin values have also been reported to be associated with organ dysfunction, coagulation disorders, and ICU mortality [27].

In the present study, presepsin cut-off values for predicting septic AKI, RRTi in sepsis patients, and prognosis in septic AKI patients were higher than those previously reported as predicting severe sepsis and septic shock [18, 19] (Tables 3 and 4). Moreover, presepsin values for predicting RRTi had a higher cut-off value and specificity relative to those for predicting septic AKI. A significant negative correlation was previously reported between presepsin levels and estimated glomerular filtration rate in both non-sepsis and sepsis patients [28]. Increases in presepsin levels in hemodialysis (HD) patients may not be related to renal dysfunction, but rather the activation of neutrophils and/or monocytes, since HD activates monocytes and/or neutrophils, which in turn leads to presepsin release from monocytes [29]. Presepsin levels in HD patients without infection were reported to be $783-2360 \mathrm{pg} / \mathrm{ml}$ [30]. Nakamura et al. retrospectively examined presepsin values in ICU 
Table 4 Receiver operating characteristic curve analysis

\begin{tabular}{|c|c|c|c|c|c|}
\hline Variable & AUC & Cut-off & $P$ value & Sensitivity & Specificity \\
\hline \multicolumn{6}{|l|}{ 28-day mortality } \\
\hline Presepsin on Day 1 (pg/mL) & 0.77 & 1373.00 & 0.004 & 0.82 & 0.77 \\
\hline Presepsin on Day 2 (pg/mL) & 0.83 & 1581.00 & 0.000 & 0.86 & 0.68 \\
\hline Presepsin on Day 3 (pg/mL) & 0.91 & 1819.00 & 0.000 & 1.00 & 0.82 \\
\hline Presepsin on Day 5 (pg/mL) & 1.00 & 3014.00 & 0.000 & 1.00 & 1.00 \\
\hline$\Delta$ Presepsin Day 2 - Day 1 (pg/mL) & 0.76 & 507.00 & 0.059 & 0.71 & 0.86 \\
\hline$\Delta$ Presepsin Day 3 - Day 1 (pg/mL) & 0.91 & -10.00 & 0.000 & 1.00 & 0.76 \\
\hline$\Delta$ Presepsin Day 5 - Day 1 (pg/mL) & 0.79 & 2385.00 & 0.176 & 0.75 & 1.00 \\
\hline iPS-PLR & 0.75 & 1.00 & 0.002 & 0.91 & 0.46 \\
\hline \multicolumn{6}{|l|}{ 60-day mortality } \\
\hline Presepsin on Day 1 (pg/mL) & 0.70 & 1373.00 & 0.063 & 0.75 & 0.76 \\
\hline Presepsin on Day 2 (pg/mL) & 0.73 & 1581.00 & 0.052 & 0.75 & 0.67 \\
\hline Presepsin on Day 3 (pg/mL) & 0.75 & 1819.00 & 0.134 & 0.80 & 0.81 \\
\hline Presepsin on Day 5 (pg/mL) & 0.80 & 3014.00 & 0.134 & 0.80 & 1.00 \\
\hline$\Delta$ Presepsin Day 2 - Day 1 (pg/mL) & 0.74 & 507.00 & 0.045 & 0.63 & 0.86 \\
\hline$\Delta$ Presepsin Day 3 - Day 1 (pg/mL) & 0.85 & -10.00 & 0.000 & 0.80 & 0.75 \\
\hline$\Delta$ Presepsin Day 5 - Day 1 (pg/mL) & 0.72 & 2385.00 & 0.238 & 0.60 & 1.00 \\
\hline iPS-PLR & 0.70 & 1.00 & 0.024 & 0.83 & 0.44 \\
\hline \multicolumn{6}{|l|}{ 90-day mortality } \\
\hline Presepsin on Day 1 (pg/mL) & 0.65 & 1373.00 & 0.142 & 0.64 & 0.74 \\
\hline Presepsin on Day 2 (pg/mL) & 0.65 & 1581.00 & 0.190 & 0.60 & 0.63 \\
\hline Presepsin on Day 3 (pg/mL) & 0.74 & 1545.00 & 0.085 & 0.83 & 0.73 \\
\hline Presepsin on Day 5 (pg/mL) & 0.79 & 1399.00 & 0.082 & 0.83 & 0.73 \\
\hline$\Delta$ Presepsin Day 2 - Day 1 (pg/mL) & 0.69 & 507.00 & 0.092 & 0.50 & 0.84 \\
\hline$\Delta$ Presepsin Day 3 - Day 1 (pg/mL) & 0.87 & -10.00 & 0.000 & 0.83 & 0.80 \\
\hline$\Delta$ Presepsin Day 5 - Day 1 (pg/mL) & 0.74 & 244.00 & 0.108 & 0.67 & 0.82 \\
\hline \multicolumn{6}{|l|}{ 180-day mortality } \\
\hline Presepsin on Day 1 (pg/mL) & 0.65 & 1336.00 & 0.121 & 0.67 & 0.68 \\
\hline Presepsin on Day 2 (pg/mL) & 0.68 & 1581.00 & 0.093 & 0.64 & 0.67 \\
\hline Presepsin on Day 3 (pg/mL) & 0.80 & 1545.00 & 0.019 & 0.86 & 0.79 \\
\hline Presepsin on Day 5 (pg/mL) & 0.77 & 1313.00 & 0.063 & 0.86 & 0.70 \\
\hline$\Delta$ Presepsin Day 2 - Day 1 (pg/mL) & 0.73 & 507.00 & 0.022 & 0.55 & 0.89 \\
\hline$\Delta$ Presepsin Day 3 - Day 1 (pg/mL) & 0.91 & -10.00 & 0.000 & 0.86 & 0.86 \\
\hline$\Delta$ Presepsin Day 5 - Day 1 (pg/mL) & 0.76 & -23.00 & 0.051 & 0.71 & 0.80 \\
\hline
\end{tabular}

AUC area under the curve, iPS inflammation-presepsin score, $P L R$ platelet to lymphocyte ratio

patients with or without sepsis, and reported that presepsin values were markedly high in patients with renal failure and end-stage kidney disease. Presepsin values in those with sepsis ranged from 2632 to $20,000 \mathrm{pg} / \mathrm{ml}$, while patients without sepsis had presepsin values of 2134 to $19,633 \mathrm{pg} / \mathrm{ml}$ [28]. In the present study, presepsin cut-off values for predicting RRTi were similar to these previously reported levels. Our results suggest the need to adopt a higher presepsin cut-off value for predicting septic AKI, RRTi in sepsis patients, and prognosis in septic AKI patients.

Cut-off values for predicting septic AKI, RRTi in sepsis patients, and prognosis in septic AKI patients on Day 2 or later after ICU entry were higher than those on Day 1 (Tables 3 and 4). Multivariate logistic regression analyses identified presepsin on Day 2 to be a predictor of prognosis in septic AKI patients (Table 7). Presepsin levels measured at the time of ICU admission may not be at an optimal level for predicting septic AKI, RRTi in sepsis 
Table 5 Log-rank test

\begin{tabular}{|c|c|}
\hline Variable & $P$ value \\
\hline \multicolumn{2}{|l|}{ 28-day mortality } \\
\hline Presepsin on Day 1 (pg/mL) & 0.00 \\
\hline Presepsin on Day 2 (pg/mL) & 0.086 \\
\hline Presepsin on Day 3 (pg/mL) & 0.126 \\
\hline Presepsin on Day 5 (pg/mL) & 0.002 \\
\hline$\Delta$ Presepsin Day 2 - Day 1 (pg/mL) & 0.014 \\
\hline$\Delta$ Presepsin Day 3 - Day 1 (pg/mL) & 0.093 \\
\hline$\Delta$ Presepsin Day 5 - Day 1 (pg/mL) & 0.008 \\
\hline PNI & 0.001 \\
\hline iPS - PLR & 0.036 \\
\hline \multicolumn{2}{|l|}{ 60-day mortality } \\
\hline Presepsin on Day 1 (pg/mL) & 0.007 \\
\hline Presepsin on Day 2 (pg/mL) & 0.170 \\
\hline Presepsin on Day 3 (pg/mL) & 0.367 \\
\hline Presepsin on Day 5 (pg/mL) & 0.003 \\
\hline$\Delta$ Presepsin Day 2 - Day 1 (pg/mL) & 0.026 \\
\hline$\Delta$ Presepsin Day 3 - Day 1 (pg/mL) & 0.223 \\
\hline$\Delta$ Presepsin Day 5 - Day 1 (pg/mL) & 0.009 \\
\hline $\mathrm{PNI}$ & 0.003 \\
\hline \multicolumn{2}{|l|}{ 90-day mortality } \\
\hline Presepsin on Day 1 (pg/mL) & 0.056 \\
\hline Presepsin on Day 2 (pg/mL) & 0.788 \\
\hline Presepsin on Day 3 (pg/mL) & 0.212 \\
\hline Presepsin on Day 5 (pg/mL) & 0.226 \\
\hline$\Delta$ Presepsin Day 2 - Day 1 (pg/mL) & 0.090 \\
\hline$\Delta$ Presepsin Day 3 - Day 1 (pg/mL) & 0.091 \\
\hline$\Delta$ Presepsin Day 5 - Day 1 (pg/mL) & 0.072 \\
\hline \multicolumn{2}{|l|}{ 180-day mortality } \\
\hline Presepsin on Day 1 (pg/mL) & 0.079 \\
\hline Presepsin on Day 2 (pg/mL) & 0.798 \\
\hline Presepsin on Day 3 (pg/mL) & 0.128 \\
\hline Presepsin on Day 5 (pg/mL) & 0.265 \\
\hline$\Delta$ Presepsin Day 2 - Day 1 (pg/mL) & 0.038 \\
\hline$\Delta$ Presepsin Day 3 - Day 1 (pg/mL) & 0.029 \\
\hline$\Delta$ Presepsin Day 5 - Day 1 (pg/mL) & 0.057 \\
\hline
\end{tabular}

PNI Prognostic Nutritional Index, iPS inflammation-presepsin score, PLR platelet to lymphocyte ratio

patients, and prognosis in septic AKI patients. Indeed, several studies have reported that presepsin levels increase as the severity of sepsis increases [13, 26, 31]. For instance, Masson et al. reported that an increase in presepsin levels from Day 1 to Day 2 after ICU admission can predict higher ICU and 90-day mortality [27]. Our findings suggest the importance of not only measuring presepsin levels at the time of ICU admission, but also monitoring its temporal changes after ICU admission in order to better predict the onset of septic AKI, RRTi in sepsis patients, and prognosis in septic AKI patients. Our findings may also provide insight on the optimal timing for RRTi in septic AKI patients.

Presepsin values increase with declining renal function [30], suggesting that the diagnostic accuracy of presepsin may be influenced by renal function. Multivariate analyses revealed that serum creatinine immediately after ICU admission (baseline) and on Day 2 were not predictors of 28-day, 60-day, 90-day, or 180-day mortality (Table 7). In contrast, presepsin immediately after ICU admission (baseline) and on Day 2 were significant predictors of 28-day mortality, even after adjusting for serum creatinine immediately after ICU admission (baseline) and on Day 2 (Table 7). These findings suggest that renal function had a minimal, if any, impact as a confounder. However, presepsin cannot be used as a single definitive index to diagnose the prognosis associated with sepsis. Thus, in addition to using presepsin, critical care physicians must comprehensively evaluate the clinical findings of each patient and make a diagnosis based on all information available.

The AUC, sensitivity, and specificity of PNI for predicting RRTi were $0.72,66.7$, and $93.5 \%$, respectively, with a higher specificity than that for presepsin alone on Days 1, 2, and 5. The corresponding median PNI values (inter-quartile range) were 18.4 (14.6-30.0) in RRTi patients and $28.9(22.7-34.1)$ in non-RRTi patients. These findings suggest that a lower PNI can predict RRTi in sepsis patients and may serve as an easy "rule in" test at the time of ICU admission. PNI can be obtained at low cost and rapidly in clinical settings where presepsin values cannot be easily measured, and provides information necessary for interventions in sepsis patients within the first few hours of ICU admission. Our findings also suggest that hypoalbuminemia and lymphocytopenia (albumin and lymphocyte counts are used to calculate PNI) are important variables for predicting RRTi in sepsis patients. Serum albumin levels are significantly correlated with presepsin levels [30]. Zahorec et al. found a correlation between severity of the clinical course and extent of lymphocytopenia in oncological ICU patients following major surgery, sepsis, and septic shock [32].

The univariate analysis revealed fibrinogen to be a significant predictor of mortality in septic AKI patients (Table 6). In the clinical setting, elevated plasma fibrinogen levels are used to predict progression or poor outcome in patients with several types of malignancies, including esophageal cancer [33], gastric cancer [34], pancreatic cancer [35], colon cancer [36], lung cancer [37], and gynecological cancer [38-40]. Elevated plasma fibrinogen might serve as a useful inflammation-based prognostic biomarker in septic AKI patients. 
Table 6 Predictors of mortality in sepsis patients (univariate analysis)

\begin{tabular}{|c|c|c|c|c|}
\hline Variable & $\begin{array}{l}\text { 28-day mortality } \\
P \text {-value }\end{array}$ & $\begin{array}{l}\text { 60-day mortality } \\
P \text {-value }\end{array}$ & $\begin{array}{l}\text { 90-day mortality } \\
P \text {-value }\end{array}$ & $\begin{array}{l}180 \text {-day mortality } \\
P \text {-value }\end{array}$ \\
\hline Age & 0.4744 & 0.6260 & 0.3081 & 0.4572 \\
\hline Sex & 0.7277 & 1.0000 & 1.0000 & 0.7341 \\
\hline Cancer & 0.1691 & 0.3193 & 0.4979 & 0.7384 \\
\hline Coronary artery disease & 1.0000 & 1.0000 & 1.0000 & 1.0000 \\
\hline Diabetes mellitus & 0.2293 & 0.2204 & 0.4339 & 0.2616 \\
\hline Hypertension & 0.4657 & 0.2863 & 0.7379 & 0.5144 \\
\hline Albumin & 0.1570 & 0.4257 & 0.2720 & 0.5150 \\
\hline CRP & 0.1579 & 0.0535 & 0.1068 & 0.1417 \\
\hline WBC & 0.4156 & 0.4654 & 0.9625 & 0.8406 \\
\hline Neutrophil & 0.4252 & 0.3468 & 0.8510 & 0.9753 \\
\hline Lymphocytes & 0.3352 & 0.7212 & 0.7541 & 0.9261 \\
\hline Platelet count & 0.1183 & 0.2699 & 0.3721 & 0.3147 \\
\hline Fibrinogen & 0.0019 & 0.0019 & 0.0026 & 0.0043 \\
\hline ARDS & 0.1249 & 0.0486 & 0.1322 & 0.2578 \\
\hline Shock & 0.7217 & 0.7110 & 0.7351 & 0.7235 \\
\hline DIC & 0.2847 & 0.4912 & 1.0000 & 1.0000 \\
\hline Presepsin on Day 1 & 0.0115 & 0.0556 & 0.1368 & 0.1257 \\
\hline Presepsin on Day 2 & 0.0093 & 0.0570 & 0.1909 & 0.1105 \\
\hline Presepsin on Day 3 & 0.0122 & 0.0986 & 0.0868 & 0.0305 \\
\hline Presepsin on Day 5 & 0.0032 & 0.0578 & 0.0562 & 0.0637 \\
\hline$\Delta$ Presepsin Day 2 - Day 1 & 0.0415 & 0.0454 & 0.1033 & 0.0366 \\
\hline$\Delta$ Presepsin Day 3 - Day 1 & 0.0122 & 0.0208 & 0.0102 & 0.0028 \\
\hline$\Delta$ Presepsin Day 5 - Day 1 & 0.0894 & 0.1706 & 0.1078 & 0.0790 \\
\hline GPS & 0.5179 & 0.2002 & 0.5073 & 0.7101 \\
\hline NLR & 0.3030 & 0.1194 & 0.3638 & 0.4036 \\
\hline PLR & 0.7649 & 0.7952 & 0.8756 & 0.5990 \\
\hline $\mathrm{Pl}$ & 0.1751 & 0.1579 & 0.6093 & 0.9329 \\
\hline $\mathrm{PNI}$ & 0.0911 & 0.4362 & 0.3014 & 0.5777 \\
\hline iPS-GPS & 0.1270 & 0.3206 & 0.3377 & 0.3436 \\
\hline iPS-NLR & 0.1220 & 0.2898 & 0.2913 & 0.4036 \\
\hline iPS-PLR & 0.0100 & 0.0365 & 0.0840 & 0.1932 \\
\hline iPS-PI & 0.2891 & 0.5490 & 0.3714 & 0.2989 \\
\hline iPS-PNI & 0.7178 & 0.1765 & 0.4710 & 0.5194 \\
\hline SOFA & 0.8806 & 0.6250 & 0.3067 & 0.4653 \\
\hline qSOFA & 0.8457 & 0.5805 & 0.2173 & 0.4010 \\
\hline
\end{tabular}

CRP C-reactive protein, WBC white blood cell, $A K I$ acute kidney injury, ARDS acute respiratory distress syndrome, DIC disseminated intravascular coagulation, GPS Glasgow Prognostic Score, NLR neutrophil to lymphocyte ratio, PLR platelet to lymphocyte ratio, PI Prognostic Index, PNI Prognostic Nutritional Index, iPS inflammation-presepsin score, SOFA Sequential Organ Failure Assessment, qSOFA quick Sequential Organ Failure Assessment

This study has several limitations. First, the present study was conducted at a single center with a small sample size. Second, we used a single biomarker, and no comparisons were made with other biomarkers.

\section{Conclusions}

Presepsin and PNI were found to be predictors of septic AKI, RRTi in sepsis patients, and prognosis in septic AKI patients. Cut-off values and specificities for 
Table 7 Multivariate analysis

\begin{tabular}{|c|c|c|c|c|}
\hline \multirow{2}{*}{\multicolumn{5}{|c|}{$\frac{\text { Variable (examined explanatory variable) }}{28-\text { day mortality (Presepsin on Day 1, Presepsin on Day 2) }}$}} \\
\hline & & & & \\
\hline Presepsin on Day 1 & 0.9989 & 0.9974 & 1.0003 & 0.120 \\
\hline Presepsin on Day 2 & 1.0018 & 1.0002 & 1.0034 & 0.027 \\
\hline \multicolumn{5}{|l|}{ 28-day mortality (Presepsin on Day 1, iPS-PLR) } \\
\hline Presepsin on Day 1 & 1.0004 & 0.9998 & 1.0010 & 0.182 \\
\hline iPS-PLR & 3.1006 & 0.7548 & 12.7370 & 0.116 \\
\hline \multicolumn{5}{|c|}{ 28-day mortality (Presepsin on Day 1, Cre on Day 1) } \\
\hline Presepsin on Day 1 & 1.0006 & 1.0001 & 1.0012 & 0.028 \\
\hline Cre on Day 1 & 0.6670 & 0.3102 & 1.4342 & 0.300 \\
\hline \multicolumn{5}{|c|}{ 28-day mortality (Presepsin on Day 2, Cre on Day 2) } \\
\hline Presepsin on Day 2 & 1.0008 & 1.0000 & 1.0015 & 0.053 \\
\hline Cre on Day 2 & 0.5674 & 0.1051 & 3.0628 & 0.510 \\
\hline \multicolumn{5}{|c|}{ 60-day mortality (Presepsin on Day 1, Presepsin on Day 2) } \\
\hline Presepsin on Day 1 & 0.9989 & 0.9975 & 1.0003 & 0.132 \\
\hline Presepsin on Day 2 & 1.0015 & 1.0001 & 1.0028 & 0.039 \\
\hline \multicolumn{5}{|l|}{ 60-day mortality (Presepsin on Day 1, iPS-PLR) } \\
\hline Presepsin on Day 1 & 1.0003 & 0.9998 & 1.0009 & 0.217 \\
\hline iPS-PLR & 2.1516 & 0.5980 & 7.7414 & 0.241 \\
\hline \multicolumn{5}{|c|}{ 60-day mortality (Presepsin on Day 1, Cre on Day 1) } \\
\hline Presepsin on Day 1 & 1.0005 & 1.0000 & 1.0010 & 0.054 \\
\hline Cre on Day 1 & 0.5945 & 0.2704 & 1.3070 & 0.196 \\
\hline \multicolumn{5}{|c|}{ 60-day mortality (Presepsin on Day 2, Cre on Day 2) } \\
\hline Presepsin on Day 2 & 1.0006 & 1.0000 & 1.0012 & 0.058 \\
\hline Cre on Day 2 & 0.4995 & 0.1077 & 2.3167 & 0.375 \\
\hline \multicolumn{5}{|c|}{ 90-day mortality (Presepsin on Day 1, Presepsin on Day 2) } \\
\hline Presepsin on Day 1 & 0.9991 & 0.9978 & 1.0004 & 0.172 \\
\hline Presepsin on Day 2 & 1.0011 & 0.9998 & 1.0023 & 0.086 \\
\hline \multicolumn{5}{|c|}{ 90-day mortality (Presepsin on Day 1, Cre on Day 1) } \\
\hline Presepsin on Day 1 & 1.0004 & 0.9999 & 1.0009 & 0.104 \\
\hline Cre on Day 1 & 0.6748 & 0.3491 & 1.3044 & 0.242 \\
\hline \multicolumn{5}{|c|}{ 90-day mortality (Presepsin on Day 2, Cre on Day 2) } \\
\hline Presepsin on Day 2 & 1.0004 & 0.9999 & 1.0009 & 0.100 \\
\hline Cre on Day 2 & 0.6546 & 0.2224 & 1.9265 & 0.442 \\
\hline \multicolumn{5}{|c|}{ 180-day mortality (Presepsin on Day 1, Presepsin on Day 2) } \\
\hline Presepsin on Day 1 & 0.9987 & 0.9972 & 1.0002 & 0.078 \\
\hline Presepsin on Day 2 & 1.0015 & 1.0001 & 1.0029 & 0.037 \\
\hline \multicolumn{5}{|c|}{ 180-day mortality (Presepsin on Day 1, Cre on Day 1) } \\
\hline Presepsin on Day 1 & 1.0004 & 0.9999 & 1.0009 & 0.124 \\
\hline Cre on Day 1 & 0.6812 & 0.3612 & 1.2850 & 0.236 \\
\hline \multicolumn{5}{|c|}{ 180-day mortality (Presepsin on Day 2, Cre on Day 2) } \\
\hline Presepsin on Day 2 & 1.0004 & 0.9999 & 1.0010 & 0.100 \\
\hline Cre on Day 2 & 0.6311 & 0.2145 & 1.8566 & 0.403 \\
\hline
\end{tabular}

$\mathrm{Cl}$ confidence interval, iPS inflammation-Presepsin Score, $P L R$ platelet to lymphocyte ratio, Cre creatinine 
predicting septic AKI and RRTi on Day 2 or later were higher than those on Day 1. Further studies aimed at understanding the exact role of presepsin values and PNI in predicting septic AKI, RRTi in sepsis patients, and prognosis in septic AKI patients are warranted.

\section{Abbreviations}

GPS: Glasgow Prognostic Score; CRP: C-reactive protein; NLR: Neutrophil to lymphocyte ratio; PLR: Platelet to lymphocyte ratio; PNI: Prognostic Nutritional Index; PI: Prognostic Index; SOFA: Sequential Organ Failure Assessment; qSOFA: Quick Sequential Organ Failure Assessment; ROC: Receiver operating characteristic; AUC: Area under the curve; RRTi: Renal replacement therapy initiation; AKI: Acute kidney injury; HD: Hemodialysis

\section{Acknowledgements}

Not applicable.

\section{Authors' contribution}

YS designed the study, collected the data, performed the statistical analysis, and wrote the first draft of the manuscript. OU, NK, and TM designed the study and revised the manuscript. All authors read and approved the final manuscript.

\section{Funding}

Not applicable.

\section{Availability of data and materials}

The datasets used and/or analyzed during the current study are available from the corresponding author on reasonable request.

\section{Declarations}

\section{Ethics approval and consent to participate}

The study protocol was approved by the Ethics Committee of Osaka Medical College (\#2206; Osaka, Japan). Written Informed consent was obtained from all patients enrolled in this study or their families.

\section{Consent for publication}

Not applicable.

\section{Competing interests}

The authors declare that they have no competing interests.

\section{Author details}

'Department of Anesthesiology, Osaka Medical College, Intensive Care Unit, Osaka Medical College Hospital, 2-7 Daigaku-machi, Takatsuki, Osaka 569-8686, Japan. ${ }^{2}$ Department of Anesthesiology, Osaka Medical College, Osaka Medical College Hospital, Takatsuki, Japan.

Received: 14 February 2021 Accepted: 3 June 2021

\section{Published online: 12 June 2021}

\section{References}

1. Singer M, Deutschman CS, Seymour CW, Shankar-Hari M, Annane D, Bauer $M$, et al. The third international consensus definitions for sepsis and septic shock (Sepsis-3). JAMA. 2016;315(8):801-10. https://doi.org/10.1001/jama.201 6.0287.

2. Vincent JL, Sakr Y, Sprung CL, Ranieri VM, Reinhart K, Gerlach H, et al. Sepsis in European intensive care units: results of the SOAP study. Crit Care Med. 2006;34(2):344-53. https://doi.org/10.1097/01.CCM.0000194725.48928.3A.

3. Murugan R, Kellum JA. Acute kidney injury: what's the prognosis? Nat Rev Nephrol. 2011;7(4):209-17. https://doi.org/10.1038/nrneph.2011.13.

4. Battleman DS, Callahan M, Thaler HT. Rapid antibiotic delivery and appropriate antibiotic selection reduce length of hospital stay of patients with community-acquired pneumonia: link between quality of care and resource utilization. Arch Intern Med. 2002;162(6):682-8. https://doi.org/10.1 001/archinte.162.6.682.

5. Kumar A, Roberts D, Wood KE, Light B, Parrillo JE, Sharma S, et al. Duration of hypotension before initiation of effective antimicrobial therapy is the critical determinant of survival in human septic shock. Crit Care Med. 2006; 34(6):1589-96. https://doi.org/10.1097/01.CCM.0000217961.75225.E9.

6. Rivers E, Nguyen B, Havstad S, Ressler J, Muzzin A, Knoblich B, et al. Early goal-directed therapy in the treatment of severe sepsis and septic shock. N Engl J Med. 2001;345(19):1368-77. https://doi.org/10.1056/NEJMoa010307.

7. Herzum I, Renz H. Inflammatory markers in SIRS, sepsis and septic shock. Curr Med Chem. 2008;15(6):581-7. https://doi.org/10.2174/092986708783 769704

8. Pierrakos C, Vincent J-L. Sepsis biomarkers: a review. Crit Care. 2010;14(1): R15. https://doi.org/10.1186/cc8872.

9. Wacker C, Prkno A, Brunkhorst FM, Schlattmann P. Procalcitonin as a diagnostic marker for sepsis: a systematic review and meta-analysis. Lancet Infect Dis. 2013;13(5):426-35. https://doi.org/10.1016/S1473-3099(12)70323-7.

10. Kibe $\mathrm{S}$, Adams K, Barlow G. Diagnostic and prognostic biomarkers of sepsis in critical care. J Antimicrob Chemother. 2011:66(Suppl 2):ii33-40.

11. Shirakawa K, Naitou K, Hirose J, Takahashi T, Furusako S. Presepsin (sCD14ST): development and evaluation of one-step ELISA with a new standard that is similar to the form of presepsin in septic patients. Clin Chem Lab Med. 2011;49(5):937-9. https://doi.org/10.1515/CCLM.2011.145.

12. Endo S, Suzuki Y, Takahashi G, Shozushima T, Ishikura H, Murai A, et al. Usefulness of presepsin in the diagnosis of sepsis in a multicenter prospective study. J Infec Chemother Official J Japan Soc Chemotherap. 2012:18(6):891-7. https://doi.org/10.1007/s10156-012-0435-2.

13. Shozushima T, Takahashi G, Matsumoto N, Kojika M, Okamura Y, Endo S Usefulness of presepsin (sCD14-ST) measurements as a marker for the diagnosis and severity of sepsis that satisfied diagnostic criteria of systemic inflammatory response syndrome. J Infect Chemother. 2011;17(6):764-9. https://doi.org/10.1007/s10156-011-0254-x.

14. Okamura Y, Yokoi H. Development of a point-of-care assay system for measurement of presepsin (sCD14-ST). Clin Chim Acta. 2011;412(23-24): 2157-61. https://doi.org/10.1016/j.cca.2011.07.024.

15. Kinoshita A, Onoda $H$, Imai $N$, Iwaku A, Oishi M, Fushiya $N$, et al. Comparison of the prognostic value of inflammation-based prognostic scores in patients with hepatocellular carcinoma. Br J Cancer. 2012;107(6): 988-93. https://doi.org/10.1038/bjc.2012.354.

16. Shimoyama Y, Umegaki O, Kadono N, Minami T. Presepsin values predict septic acute kidney injury, acute respiratory distress syndrome, disseminated intravascular coagulation, and shock. Shock. 2020. https://doi.org/10.1097/ SHK.00000000000001664 Online ahead of print.

17. KDIGO Guideline. Kidney disease: improving global outcomes. Clinical practice guideline on acute kidney injury 2011. http://www.kdigo.org. Accessed 4 April 2012

18. Chenevier-Gobeaux C, Borderie D, Weiss N, Mallet-Coste T, Claessens Y-E. Presepsin (sCD14-ST), an innate immune response marker in sepsis. Clin Chim Acta. 2015:450:97-103.

19. Carpio R, Zapata J, Spanuth E, Hess G. Utility of presepsin (SCD14-ST) as a diagnostic and prognostic marker of sepsis in the emergency department. Clin Chim Acta. 2015;450:169-75

20. Hotchkiss RS, Monneret G, Payen D. Sepsis-induced immunosuppression: from cellular dysfunctions to immunotherapy. Nat Rev Immunol. 2013; 13(12):862-74. https://doi.org/10.1038/nri3552.

21. Levy MM, Fink MP, Marshall JC, Abraham E, Angus D, Cook D, et al. SCCM/ ESICM/ACCP/ATS/SIS international sepsis definitions conference. Intensive Care Med. 2001;2003(29):530-8.

22. Calandra T, Cohen J. The international sepsis forum consensus conference on definitions of infection in the intensive care unit. Crit Care Med. 2005;33(7):1538-48. https://doi.org/10.1097/01.CCM.00001682 53.91200 .83$.

23. Tunkel AR, Hartman BJ, Kaplan SL, Kaufman BA, Roos KL, Scheld WM, et al. Practice guidelines for the management of bacterial meningitis. Clin Infect Dis. 2004;39(9):1267-84. https://doi.org/10.1086/425368.

24. Angus DC, Linde-Zwirble WT, Lidicker J, Clermont G, Carcillo J, Pinsky MR. Epidemiology of severe sepsis in the United States: analysis of incidence, outcome and associated costs of care. Crit Care Med. 2001;29(7):1303-10. https://doi.org/10.1097/00003246-200107000-00002.

25. Naitoh K, Shirakawa K, Hirose J, Nakamura M, Takeuchi T, Hosaka Y, et al. The new sepsis marker, sCD14-ST (PRESEPSIN): induction mechanism in the rabbit sepsis models. Crit Care. 2010;14:P19.

26. Liu B, Chen Y-X, Yin Q, Zhao Y-Z, Li C-S. Diagnostic value and prognostic evaluation of Presepsin for sepsis in an emergency department. Crit Care. 2013;17(5):R244. https://doi.org/10.1186/cc13070 
27. Masson S, Caironi P, Fanizza C, Thomae R, Bernasconi R, Noto A, et al. Circulating presepsin (soluble CD14 subtype) as a marker of host response in patients with severe sepsis or septic shock: data from the multicenter, randomized ALBIOS trial. Intensive Care Med. 2015;41(1):12-20. https://doi. org/10.1007/s00134-014-3514-2.

28. Nakamura $Y$, Ishikura $H$, Nishida $T$, Kawano $Y$, Yuge $R$, Ichiki $R$, et al. Usefulness of presepsin in the diagnosis of sepsis in patients with or without acute kidney injury. BMC Anesthesiol. 2014;14(1):88. https://doi. org/10.1186/1471-2253-14-88

29. Takahashi G, Shibata S, Fukui Y, Okamura Y, Inoue Y. Diagnostic accuracy of procalcitonin and presepsin for infectious disease in patients with acute kidney injury. Diagn Microbiol Infect Dis. 2016;86(2):205-10. https://doi.org/1 0.1016/j.diagmicrobio.2016.07.015.

30. Nagata T, Yasuda Y, Ando M, Abe T, Katsuno T, Kato S, et al. Clinical impact of kidney function on Presepsin levels. PLoS One. 2015;10(6):e0129159. https://doi.org/10.1371/journal.pone.0129159.

31. Behnes M, Bertsch T, Lepiorz D, Lang S, Trinkmann F, Brueckmann M, et al. Diagnostic and prognostic utility of soluble CD 14 subtype (presepsin) for severe sepsis and septic shock during the first week of intensive care treatment. Crit Care. 2014;18(5):507. https://doi.org/10.1186/s13054-014-0507-z.

32. Zahorec. Ratio of neutrophil to lymphocyte counts - rapid and simple parameter of systemic inflammation and stress in critically ill. Bratisl Lek Listy. 2001;102(1):5-14.

33. Takeuchi H, Ikeuchi S, Kitagawa Y, Shimada A, Oishi T, Isobe Y, et al. Pretreatment plasma fibrinogen level correlates with tumor progression and metastasis in patients with squamous cell carcinoma of the esophaqus. J Gastroenterol Hepatol. 2007;22(12):2222-7. https://doi.org/10.1111/j.1440-1 746.2006.04736.x.

34. Yamashita H, Kitayama J, Kanno N, Yatomi Y, Nagawa H. Hyperfibrinogenemia is associated with lymphatic as well as hematogenous metastasis and worse clinical outcome in T2 gastric cancer. BMC Cancer. 2006;6(1):147. https://doi.org/10.1186/1471-2407-6-147.

35. Guo Q, Zhang B, Dong X, Xie Q, Guo E, Huang H, et al. Elevated levels of plasma fibrinogen in patients with pancreatic cancer: possible role of a distant metastasis predictor. Pancreas. 2009:38(3):e75-9. https://doi.org/10.1 097/MPA.0b013e3181987d86.

36. Tang L, Liu K, Wang J, Wang C, Zhao P, Liu J. High preoperative plasma fibrinogen levels are associated with distant metastases and impaired prognosis after curative resection in patients with colorectal cancer. J Surg Oncol. 2010;102(5):428-32. https://doi.org/10.1002/jso.21668.

37. Jones JM, McGonigle NC, McAnespie M, Cran GW, Graham AN. Plasma fibrinogen and serum C-reactive protein are associated with non-small cell lung cancer. Lung Cancer. 2006;53(1):97-101. https://doi.org/10.1016/j. lungcan.2006.03.012.

38. Polterauer S, Grimm C, Seebacher V, Concin N, Marth C, Tomovski C, et al. Plasma fibrinogen levels and prognosis in patients with ovarian cancer: a multicenter study. Oncologist. 2009;14(10):979-85. https://doi.org/10.1634/ theoncologist.2009-0079.

39. Polterauer S, Seebacher V, Hefler-Frischmuth K, Grimm C, Heinze G, Tempfer C, et al. Fibrinogen plasma levels are an independent prognostic parameter in patients with cervical cancer. Am J Obstet Gynecol. 2009;200:647 e1-647.e7.

40. Seebacher V, Polterauer S, Grimm C, Husslein H, Leipold H, Hefler-

Frischmuth $\mathrm{K}$, et al. The prognostic value of plasma fibrinogen levels in patients with endometrial cancer: a multi-Centre trial. Br J Cancer. 2010; 102(6):952-6. https://doi.org/10.1038/sj.bjc.6605547.

\section{Publisher's Note}

Springer Nature remains neutral with regard to jurisdictional claims in published maps and institutional affiliations.

Ready to submit your research? Choose BMC and benefit from:

- fast, convenient online submission

- thorough peer review by experienced researchers in your field

- rapid publication on acceptance

- support for research data, including large and complex data types

- gold Open Access which fosters wider collaboration and increased citations

- maximum visibility for your research: over $100 \mathrm{M}$ website views per year

At BMC, research is always in progress.

Learn more biomedcentral.com/submissions 